\title{
Oxidation process of the steel/nc-TiC nanocomposites
}

\author{
P. Figiel $\cdot$ W. Biedunkiewicz $\cdot$ D. Grzesiak
}

ICMVTT2011 Conference Special Chapter

(C) The Author(s) 2011. This article is published with open access at Springerlink.com

\begin{abstract}
Ceramic composites are widely used in various technologies such as tool production, aerospace technology, and nuclear power engineering. Their key features are considerable hardness and resistance to wear and corrosion at high temperature. Because many ceramic nanocomposites are designed to work at high temperature, it is important to determine their high temperature corrosion resistance. The subject of the investigation in this study were nanocomposite MMC (metal matrix composite) materials. As matrix the 316L stainless steel was used and the filler (nanoparticles) was nc-TiC. Using carbonized and purified nc-TiC particles the technology of the production of the nanocomposite structures based on the selective laser melting (SLM) technology was worked out. The MCP HEK Realizer II device was applied. The particles have been depicted by TEM method, whereas characterization of structure and particles size was performed by XRD method. The results of investigations on oxidation process of the steel/ncTiC nanocomposites in dry air have been presented. TG-DSC measurements were carried out under non-isothermal conditions at linear change of samples temperature in time and under isothermal conditions. MS method was used to determine evolved gaseous products.
\end{abstract}

Keywords MMC - Nanocomposite - Oxidation · SLS · SLM

\footnotetext{
P. Figiel $(\bowtie)$

Institute of Materials Science and Engineering West Pomeranian University of Technology, Szczecin, Piastow Av. 19, Szczecin, Poland

e-mail: pfigiel@zut.edu.pl

W. Biedunkiewicz · D. Grzesiak

Institute of Mechanical Technology West Pomeranian University

of Technology, Szczecin, Piastow Av. 19, Szczecin, Poland
}

\section{Introduction}

Carbides of transition metals belong to the group of ceramic materials known as conventionally hard materials. This is effect of the character of chemical bound, crystallographic structure, and morphology. Nanocrystalline materials, play ing the part of one of the phases of nanocomposite, can contribute to the occurrence of strengthening phenomena not existing in conventional materials of micrometric size.

Metal matrix composites (MMCs) are the focus of intense research and development worldwide for many industrial branches, where reduction in weight of elements along with the improvement in specific modulus, strength, thermal stability, wear resistance, and service life are required [1-4]. One of the ways for obtaining functional nanocomposite materials is the technology based on the selective laser melting of powder. This method belongs to promising rapid prototyping (RP) processes because of its ability to fabricate three-dimensional (3D) metal parts directly according to CAD model [5].

The study presents an experimental investigation about the oxidation process of the nc-TiC in $316 \mathrm{~L}$ steel matrix nanocomposites prepared by selective laser sintering/ melting (SLS/M) method using commercial 316L stainless steel powder and nanocrystalline titanium carbide powder as raw materials. The results of research on oxidation in dry air of nc-TiC/316L steel nanocomposites, reference 316L steel obtained by SLS/M method and of the used powders have been presented. The oxidation process was studied on the basis of TG-DSC-MS measurements.

\section{Experimental}

The original way of ceramic nanomaterials synthesis based on non-hydrolytic sol-gel method was elaborated [6, 7]. 
Fig. 1 a TEM micrograph and b electron diffraction image of purified nc-TiC powder
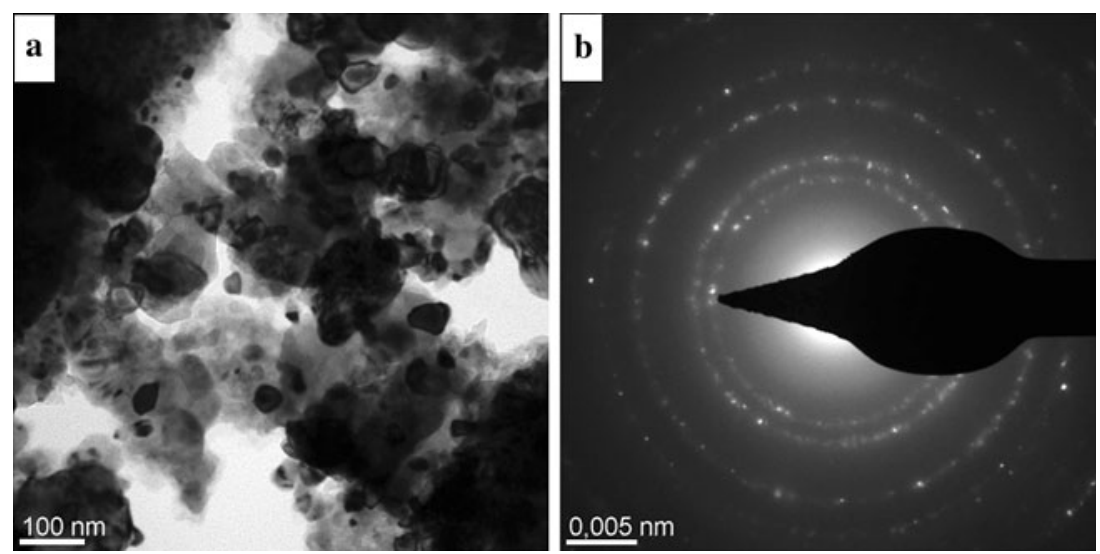

Using carbonized and purified nc-TiC particles the technology of production of nanocomposite structures based on the selective laser sintering/melting (SLS/M) technology was worked out. The MCP HEK Realizer II device was applied. The suitable gear and the modification of the parameters of the laser energy delivering allowed to use the device for work in the Partial Melting technology. Such configuration enables the research on obtainment of the nanocomposite material. As matrix the stainless steel (AISI $316 \mathrm{~L}$ ) and as the filler (nanoparticles) $\mathrm{nc}^{-\mathrm{TiC}_{0,85}}$ was used. Nanocomposite (TiC/steel) and reference (316L steel) samples for testing were formed by SLS/M technique in shape of balls of $3 \mathrm{~mm}$ diameter and of mass in the order of $160 \mathrm{mg}$. In the SLS/M process following parameters were used:

Ten vol.\% of nc-TiC in steel matrix, the power of the laser equal to $5000 \mathrm{~mA}$. Nanoparticles size, chemical and phase composition were determined with the following techniques: XRD (PANalytical PW3040/60 X'Pert Pro), TEM (JEOL JEM 1200EX).

The investigations on the oxidation process were carried out by thermoanalytical method using TG-DSC (SDT Q600, TA) coupled with MS (Thermostar GDS 301 Pfeiffer Vacuum) for gaseous products identification. Measurements were performed under non-isothermal $\left(\beta=10 \mathrm{~K} \mathrm{~min}^{-1}\right)$ conditions, in temperature range from 298 to 1473 K. During the measurements temperature of the samples and TG, DTG, HF functions in time were registered. The mixed powder containing 10 vol.\% of $\mathrm{nc}^{-\mathrm{TiC}_{0,85}}$ and 90 vol.\% of $316 \mathrm{~L}$ steel, the sintered $316 \mathrm{~L}$ steel and the sintered nanocomposite containing $10 \mathrm{vol} . \%$ of $\mathrm{nc}^{-\mathrm{TiC}_{0,85}}$ in the $316 \mathrm{~L}$ steel matrix were subjected to oxidation process.

\section{Results}

The average size of nc-TiC crystallites was in the order of $40 \mathrm{~nm}$ (Fig. 1). The powders mixed in ball mill before introducing them into the Realizer II device allowed obtaining of non-porous composites with uniform dispersion of nc-TiC particles embedded in the 316L steel matrix. $\mathrm{X}$-Ray diffraction pattern of the nanocomposite is presented in Fig. 2.

The composite material, containing nc- $\mathrm{TiC}_{0,85}$, obtained by SLS/M technique was characterized by satisfying dispersion of particles in steel matrix and increased hardness comparing to reference sample prepared from $316 \mathrm{~L}$ steel powder [8].

In Fig. 3, the plots of $\mathrm{TG}_{\mathrm{u}}$ function in time and in Fig. 4 plots of DTG function in temperature of sintered samples composed of.

$10 \mathrm{vol} . \% \mathrm{nc}-\mathrm{TiC}$ particles in steel matrix and of the reference steel sample, both heated in synthetic air, are compared.

In Fig. 5, the DTG function and $\mathrm{CO}_{2}$ spectrum are presented, whereas in Fig. $6 \mathrm{TG}$ and HF functions dependency on temperature for the oxidized sintered $316 \mathrm{~L}$ steel are presented.

Process of sintered 316L steel oxidation started at temperature of $1107 \mathrm{~K}$. Simultaneously burning of structural carbon $\left(\mathrm{CO}_{2}\right.$ evolution) took place. In oxidation process of 316 steel three stages have been distinguished. In the first stage mass growth was in the order of $0.135 \mathrm{wt} \%$, in the

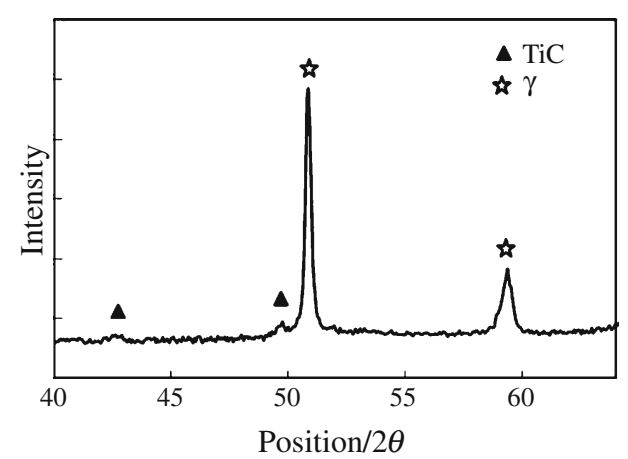

Fig. 2 X-Ray diffraction pattern of the composite containing $10 \mathrm{wt} \%$ of $\mathrm{nc}^{-\mathrm{TiC}_{0,85}}$ in steel matrix 


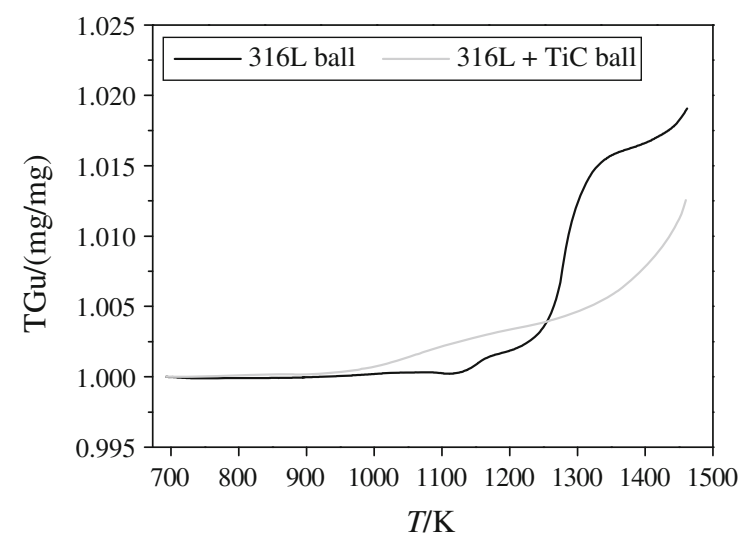

Fig. 3 Comparison of the $\mathrm{TG}_{\mathrm{u}}$ curves for oxidation processes of the sintered 316L steel and the $316 \mathrm{~L}$ steel/TiC (10 vol.\%) nanocomposite, $10 \mathrm{~K} \mathrm{~min}^{-1}$ up to $1,473 \mathrm{~K}$

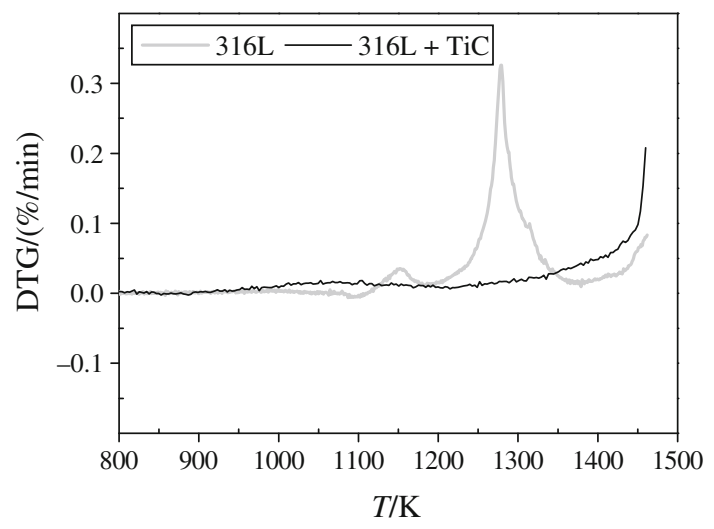

Fig. 4 Comparison of the DTG curves for oxidation processes of the sintered $316 \mathrm{~L}$ steel and the $316 \mathrm{~L}$ steel/TiC (10 vol.\%) nanocomposite, $10 \mathrm{~K} \mathrm{~min}^{-1}$ up to $1,473 \mathrm{~K}$

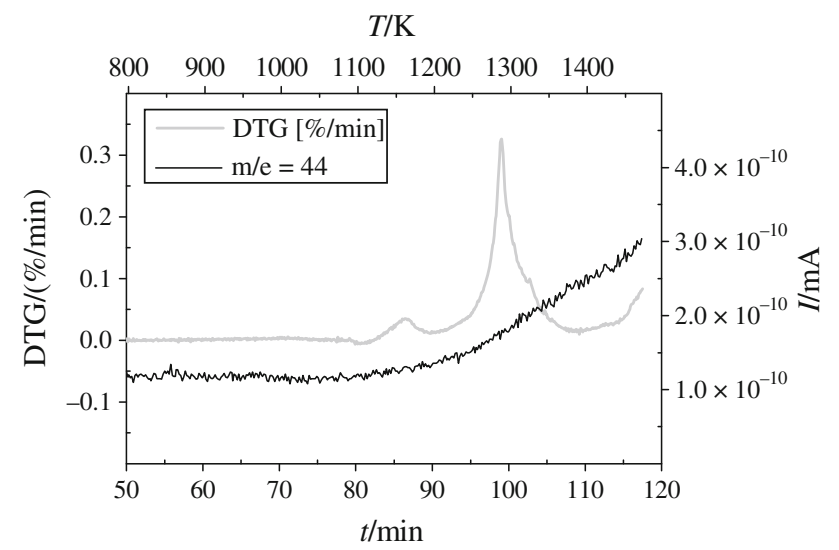

Fig. 5 DTG function and $\mathrm{CO}_{2}$ mass spectrum in time. Oxidation of the sintered $316 \mathrm{~L}$ steel in air, $10 \mathrm{~K} \mathrm{~min}^{-1}$ up to $1,473 \mathrm{~K}$

second stage of $1,454 \%$, and the third stage has not been finished.

Process of nanocomposite oxidation started at temperature of $936 \mathrm{~K}$. In this process two stages have been

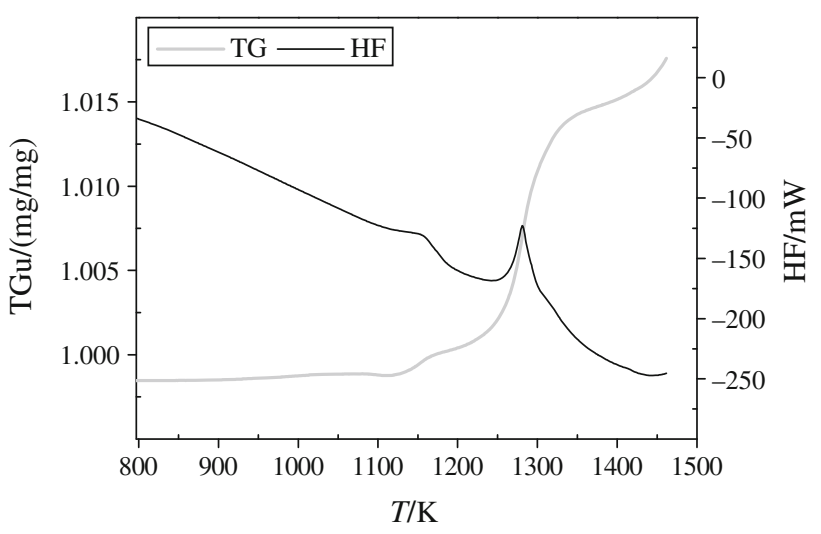

Fig. 6 Dependency of $\mathrm{TG}$ and $\mathrm{HF}$ functions on temperature. Oxidation of the sintered $316 \mathrm{~L}$ steel in air, $10 \mathrm{~K} \mathrm{~min}^{-1}$ up to $1,473 \mathrm{~K}$

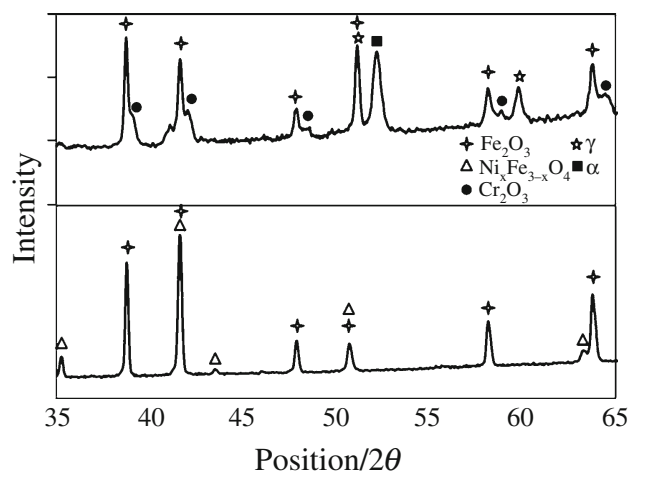

Fig. 7 X-Ray diffraction pattern of the nanocomposite containing $10 \mathrm{vol} . \%$ of nc-TiC (a) and the $316 \mathrm{~L}$ steel (b) after oxidation

distinguished. In temperature range of $930-1,200 \mathrm{~K}$, the first stage finished and the second stage started.

In Fig. 7, the comparison of the diffraction patterns of steel and nanocomposite after oxidation at heating rate of $10 \mathrm{~K} \mathrm{~min}^{-1}$ up to $1,473 \mathrm{~K}$ are presented.

Among the oxidation products of both materials phases with structures corresponding to $\mathrm{Fe}_{2} \mathrm{O}_{3}$ and $\mathrm{Ni}_{\mathrm{x}} \mathrm{Fe}_{3-\mathrm{x}} \mathrm{O}_{4}$ have been found. In case of sintered steel probably phases reacher in nickel, and in case of composite phases reacher in iron occured. Peaks from austenite and ferrite present in XRD spectrum give evidence that the products of nanocomposite oxidation form a thin layer. In the thin layer of products of nanocomposite oxidation some small fractions of phase rich in chromium, $\mathrm{Cr}_{2} \mathrm{O}_{3}$, have been additionally identified.

Analysis of phase composition of oxidation products confirmed observations made on the samples after oxidation process. The surface of nanocomposite was covered by thin passive layer with very good adherence to the 


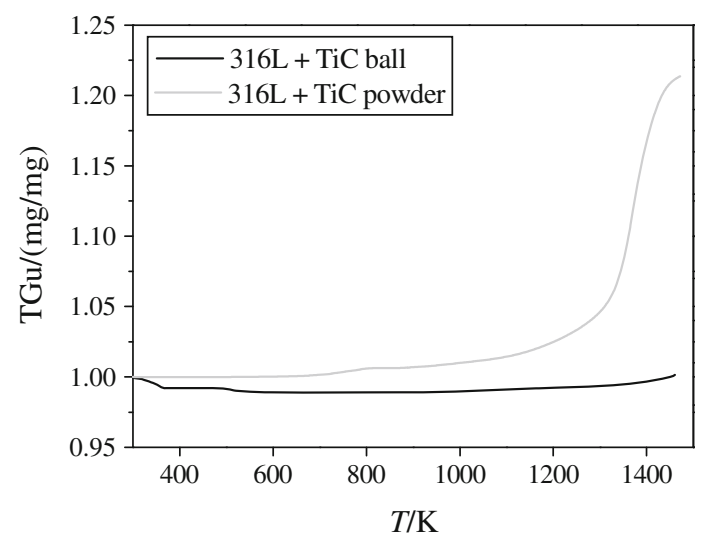

Fig. 8 Comparison of the dependency of $\mathrm{TG}_{\mathrm{u}}$ function on temperature for composites in form of sintered ball and powder. Oxidation of the $316 \mathrm{~L}$ steel/TiC (10 wt $\%), 10 \mathrm{~K} \mathrm{~min}^{-1}$ upto $1,473 \mathrm{~K}$

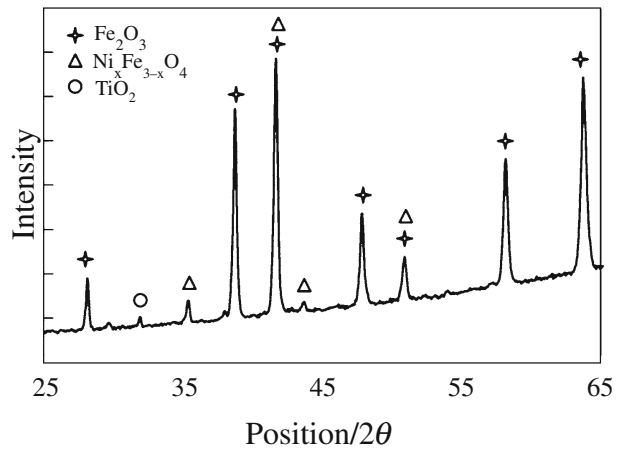

Fig. $9 \mathrm{X}$-Ray diffraction pattern of the powder containing $10 \mathrm{wt} \%$ of $\mathrm{nc}^{-\mathrm{TiC}_{0.85}}$ and $90 \mathrm{wt} \%$ of $316 \mathrm{~L}$ steel after oxidation

composite substrate, containing besides iron oxides additionally chromium oxides, whereas in the thick, porous layer of scale, characterized by poor adhesion to $316 \mathrm{~L}$ steel, hematite and magnetite rich in nickel dominated, what was confirmed by the results of the studies [9-13].

In Fig. 8,the dependency of $\mathrm{TG}_{\mathrm{u}}$ function on temperature of ball sample composed of $10 \mathrm{vol} . \%$ nc-TiC particles in steel matrix and the powder sample composed of $10 \mathrm{vol} . \% \mathrm{nc}-\mathrm{TiC}$ and $90 \mathrm{vol} . \% 316 \mathrm{~L}$ steel heated at rate of $10 \mathrm{~K} \mathrm{~min}^{-1}$ up to $1,473 \mathrm{~K}$ in air have been presented. There was stated that the oxidation process of the powder starts at the temperature about 240 degrees lower in comparison to the sinter of the same composition.

Analysis of phase composition of mixed powder, composed of $90 \mathrm{vol} . \%$ of $316 \mathrm{~L}$ steel and nc-TiC (10 vol.\%) heated in dry air at rate of $10 \mathrm{~K} \mathrm{~min}^{-1}$ up to $1,473 \mathrm{~K}$, performed by XRD method (Fig. 9) showed the presence of the following oxidation products: $\mathrm{Fe}_{2} \mathrm{O}_{3}, \mathrm{Ni}_{x} \mathrm{Fe}_{3-x} \mathrm{O}_{4}$ and $\mathrm{TiO}_{2}$ (rutile).

\section{Conclusions}

The results of the oxidation processes of 316L steel and composite containing $10 \mathrm{vol} . \%$ of $\mathrm{nc}^{-\mathrm{TiC}_{0,85}}$ in $316 \mathrm{~L}$ steel matrix sintered by SLS/M method and of the mixed powder have been compared.

It was stated that the nanocomposite material was characterized by better resistance to oxidation in air at high temperatures comparing to sintered $316 \mathrm{~L}$ steel. After heating in dry air up to temperature of $1473 \mathrm{~K}$ at heating rate of $10 \mathrm{~K} \mathrm{~min}^{-1}$ on the surface of $316 \mathrm{~L}$ steel/nc-TiC nanocomposite the thin passive layer was formed. In this layer, besides $\mathrm{Fe}_{2} \mathrm{O}_{3}$ and $\mathrm{Ni}_{x} \mathrm{Fe}_{3-x} \mathrm{O}_{4}, \mathrm{Cr}_{2} \mathrm{O}_{3}$ was identified by XRD method. Among the oxidation products of sintered steel two phases were identified: $\mathrm{Fe}_{2} \mathrm{O}_{3}$ and $\mathrm{Ni}_{x} \mathrm{Fe}_{3-x} \mathrm{O}_{4}$. Products of sintered steel oxidation formed thicker, loose layer of rust. Among the oxidation products of the mixed powder containing $10 \mathrm{vol} . \%$ of $\mathrm{nc}^{-\mathrm{TiC}_{0,85}}$ and $90 \mathrm{vol} . \%$ of $316 \mathrm{~L}$ steel no $\mathrm{Cr}_{2} \mathrm{O}_{3}$ was found, whereas $\mathrm{TiO}_{2}$ (rutile) was identified. The process started at the temperature about 240 degrees lower in comparison to the sinter of the same composition.

The obtained results suggest that the nanocomposite oxidation proceeds according to different mechanism comparing to the mechanism of powder oxidation. The formed $\mathrm{Cr}_{2} \mathrm{O}_{3}$ is probably responsible for increased oxidation resistance of nanocomposite obtained by SLS/M method.

Open Access This article is distributed under the terms of the Creative Commons Attribution Noncommercial License which permits any noncommercial use, distribution, and reproduction in any medium, provided the original author(s) and source are credited.

\section{References}

1. Tong L, Reddy RG. In situ synthesis of TiC-Al(Ti) nanocomposite powders by thermal plasma technology. Metall Mater Trans B. 2006;37B:531-9.

2. Surender M, Balasubramaniam R, Basu B. Electrochemical behavior of electrodeposited Ni-WC composite coatings. Surf Coat Technol. 2004;187:93-7.

3. Pagounis E, Lindroos VK. Processing and properties of particulate reinforced steel matrix composites. Mater Sci Eng A. 1998; 246:221-34.

4. Das K, Bandyopadhyay TK, Das S. A review on these various synthesis routes of $\mathrm{TiC}$ reinforced ferrous based composites. J Mater Sci. 2002;37:3881-92.

5. Wang Li, Sun YS, Fan Q, Xue F, Duan ZC. Tensile and wear properties of $\mathrm{TiC}$ reinforced 420 stainless steel fabricated by in situ synthesis. J Southeast Univ. 2004;20(4):486-91.

6. Biedunkiewicz A, Gabriel U, Figiel P, Grzesiak D. Application of thermal analysis in nanotechnology, carbonization and purification of $\mathrm{nc}^{-\mathrm{TiC}_{x}}$ in argon atmosphere. $\mathrm{J}$ Therm Anal Calorim. 2010;101(2):701-6.

7. Biedunkiewicz A, Wysiecki M, Noworol P. Organotitanium precursor and method of producing and processing of organotitanium precursor. Polish Patent. 2008. P200978. 
8. Biedunkiewicz A, Biedunkiewicz W, Figiel P, Grzesiak D. Preparation of stainless steel-TiC composite by selective laser melting. Chem Listy. 2011;105:773-4.

9. Bautista A, Velasco F, Campos M, Rabanal ME, Torralba JM. Oxidation behavior at $900{ }^{\circ} \mathrm{C}$ of austenitic, ferritic and duplex sainless steels manufactured by powder metallurgy. Oxid Met. 2003;59(3/4):373-93.

10. Buscail H, Messki SE, Riffard F, Perrier S, Cueff R, Caudron E, Issartel C. Characterization of the oxides formed at $1,000{ }^{\circ} \mathrm{C}$ on the AISI $316 \mathrm{~L}$ stainless steel-role of molybdenum. Mater Chem Phys. 2008;111:491-6.
11. Buscail H, Messki SE, Riffard F, Perrier S, Cueff R, Caudron E, Issartel C. Role of molybdenum on the AISI 316L oxidation at $900{ }^{\circ}$ C. J Mater Sci. 2008;43:6960-6.

12. Vourlias G, Pistofidis N, Pavlidou E, Chrissafis K. Oxidation behaviour of precipitation hardened steel TG, X-Ray, XRD and SEM study. J Therm Anal Calorim. 2009;95(1):63-8.

13. Vourlias G, Pistofidis N, Psyllaki P, Pavlidou E, Chrissafis K. Initial stages of oxidation of a precipitation-hardening $(\mathrm{PH})$ steel. J Therm Anal Calorim. 2010;101:893-8. 